\title{
The importance of comorbidity in the presence of low culture positivity in a education and research hospital in Istanbul
}

\author{
Armagan Filik ( $\sim$ armaganfilik@gmail.com ) \\ Agrı patnos state hospital https://orcid.org/0000-0001-9443-3146 \\ Hulya Gungel \\ Saglik Bilimleri Universitesi \\ Tulin OGREDEN \\ Kagoshima Daigaku - Sakuragaoka Campus
}

Keywords:

Posted Date: April 7th, 2021

DOI: https://doi.org/10.21203/rs.3.rs-371287/v1

License: (c) (i) This work is licensed under a Creative Commons Attribution 4.0 International License.

Read Full License 


\section{Abstract}

The authors have requested that this preprint be removed from Research Square. 